\title{
Anabases
}

ANABASES Traditions et réceptions de l'Antiquité

$20 \mid 2014$

Varia

\section{Laure HERMAND-SCHEBAT, Pétrarque épistolier et Cicéron. Étude d'une filiation}

Anne-Hélène Klinger-Dollé

\section{OpenEdition}

Journals

Édition électronique

URL : http://journals.openedition.org/anabases/5154

DOI : 10.4000/anabases.5154

ISSN : 2256-9421

Éditeur

E.R.A.S.M.E.

Édition imprimée

Date de publication : 1 novembre 2014

Pagination : 414-416

ISSN : 1774-4296

\section{Référence électronique}

Anne-Hélène Klinger-Dollé, "Laure hermand-schebat, Pétrarque épistolier et Cicéron. Étude d'une filiation », Anabases [En ligne], 20 | 2014, mis en ligne le 01 novembre 2014, consulté le 22 septembre 2020.

URL : http://journals.openedition.org/anabases/5154; DOI : https://doi.org/10.4000/anabases.5154

Ce document a été généré automatiquement le 22 septembre 2020.

(c) Anabases 


\title{
Laure HERMAND-SCHEBAT, Pétrarque épistolier et Cicéron. Étude d'une filiation
}

\author{
Anne-Hélène Klinger-Dollé
}

\section{RÉFÉRENCE}

Laure HERMAND-SCHEBAT, Pétrarque épistolier et Cicéron. Étude d'une filiation, Paris, PUPS, $2011,577 \mathrm{p}$.

28 euros / ISBN 978-2-84050-655-3

1 Ce beau livre, issu d'une thèse de doctorat, guide avec clarté, élégance et grande érudition son lecteur dans l'univers de Pétrarque, avec pour dessein de cerner la manière dont « le mythe pétrarquien de l'humaniste se construit autour de la figure de Cicéron » (p. 20). La méthode dépasse le seul cadre de l'intertextualité, et l'analyse de nombreuses passages de la correspondance de Pétrarque relatifs à Cicéron - l'homme et l'œuvre -, la comparaison entre des options philosophiques essentielles des deux hommes ou entre leurs pratiques d'un même genre, telles la lettre et la consolation, s'avèrent tout aussi riches d'enseignements que le repérage de citations, explicites ou cachées. L'entreprise est vaste, plus encore que le titre ne le laisse présager. En effet, l'étude explore deux énormes corpus : d'une part les Lettres familières et les Lettres de la vieillesse de Pétrarque (respectivement 350 et 128 lettres), avec des incursions importantes dans les traités philosophico-religieux (De uita solitaria, De ignorantia, De otio religioso, Secretum notamment); d'autre part, l'ensemble de l'œuvre cicéronienne ouvrages rhétoriques, discours, œuvres philosophiques, correspondance, avec une attention plus spécifique, annoncée dès l'introduction, aux Tusculanes, au De oratore, à l' Orator et aux Lettres à Atticus. Plus encore, l'auteur s'attache à montrer comment la réception de Cicéron par Pétrarque s'ancre dans les approches de l'Antiquité tardive (Augustin, plutôt que Jérôme) et du Moyen Âge. Elle offre aussi des aperçus intéressants 
sur la manière dont Pétrarque a souvent ouvert la voie aux humanistes du Quattrocento - Coluccio Salutati, Poggio Bracciolini, Politien...

2 La première partie contient le préalable indispensable aux suivantes. Parfois technique, elle offre un bilan actualisé des connaissances relatives au travail philologique de Pétrarque sur l'œuvre cicéronienne: identification des écrits de Cicéron connus de Pétrarque (avec le détail des manuscrits qu'il a possédés et annotés), rôle de Pétrarque dans l'élaboration de la tradition textuelle cicéronienne, nature des annotations de Pétrarque. Une présentation synthétique de la diffusion de Cicéron au Moyen Âge permet de mieux cerner ce qui change avec Pétrarque : ainsi son éloquence n'est plus abordée uniquement par le biais théorique du De inventione, très lu au Moyen Âge, mais par les discours mêmes; plus encore la Correspondance à Atticus, pratiquement disparue au Moyen Âge, est remise au jour par Pétrarque en 1345. L'auteur donne un exemple amusant de la manière dont les éditions modernes sous-estiment souvent l'apport de l'humaniste. L'éditeur scientifique du Pro Archia aux Belles Lettres écrit ainsi : «Un certain nombre de mss., de date récente ( $\mathrm{XIV}^{\mathrm{e}} \mathrm{ou} \mathrm{Xv}^{\mathrm{e}}$ siècle), n'ont d'autre intérêt que de présenter çà et là les corrections de quelque érudit inconnu » (p. 134, n. 59), périphrase derrière laquelle se cache en réalité le travail de Pétrarque, dont l'auteur montre au contraire la pertinence.

3 La deuxième et la troisième parties, intitulées « Regards traditionnels sur Cicéron » et "Regards novateurs sur Cicéron", cherchent à dégager plusieurs aspects de la réception de Cicéron par Pétrarque, les uns davantage dans la continuité de la réception tardo-antique et médiévale, les autres identifiés au contraire comme nouveaux. La deuxième partie aborde successivement Cicéron comme orator, situant Pétrarque dans la lignée plutôt qu'en rupture de l'ars dictaminis (art d'écrire les lettres qui se développent dans les administrations curiale, municipale, impériale, en Italie à partir du XII siècle), comme philosophe, en particulier comme relais du stoïcisme, enfin comme modèle de Pétrarque lui-même dans son projet de rétablir l'unité entre rhétorique et philosophie. L'auteur, tout en mobilisant de nombreuses références critiques, n'hésite pas à indiquer clairement ses points de dissension ; elle combat ainsi vigoureusement le contresens réalisé par Theodor Mommsen sur l'expression de media aetas, longtemps repris par la critique, selon lequel Pétrarque serait l'initiateur du concept de "Moyen Âge » comme âge obscur dont les humanistes se différencieraient. Si Pétrarque ne crédite pas les auteurs médiévaux de la même aura que les auteurs antiques, puisqu'il ne les mentionne pas, son approche de Cicéron présente des affinités avec certains lettrés médiévaux qui furent de fin connaisseur de l'écrivain antique: Loup de Ferrières (IX ${ }^{\mathrm{e}}$ siècle), Jean de Salisbury ( $\mathrm{xII}^{\mathrm{e}}$ siècle).

4 La troisième partie comporte trois gros dossiers passionnants. Tout d'abord, l'auteur montre comment Pétrarque initie un débat nouveau, «fécond pour l'humanisme » et qui se poursuivra de 1390 à 1420, autour de la personnalité de Cicéron; la découverte des Lettres à Atticus amène en effet Pétrarque à prôner une attitude critique, capable de prendre ses distances avec le comportement de l'homme politique, jugé en contradiction avec le philosophe. Le deuxième temps est consacré à la question cruciale pour Pétrarque - du rapport entre Cicéron et la pensée chrétienne. Alors que le Moyen Âge n'a pas tenté de "christianisation " poussée de Cicéron, à l'inverse de ce qu'il a fait pour Virgile ou Sénèque, Pétrarque s'efforce de montrer la compatibilité de l'œuvre cicéronienne avec le christianisme, tout en maintenant la conscience des différences. L'auteur étudie la manière dont Pétrarque retravaille la pensée 
cicéronienne à travers la tradition chrétienne, et vice-versa, à propos de quatre notions ou thèmes : l'otium (développements qui nous ont paru particulièrement suggestifs), l' amicitia, les passions (libidines) et la mort. Le troisième temps, intitulé «Cicéron ou l'autre moi", explore la conception de la lecture comme amitié fondée sur la ressemblance des esprits (similitudo ingeniorum), et passant par une identification de Pétrarque avec Cicéron. Cette « construction littéraire » est un des moyens privilégiés par lesquels Pétrarque érige sa propre vie en mythe littéraire. Or c'est bien le rôle de Cicéron dans la dynamique de l'écriture pétrarquienne qui est au cœur de la quatrième partie.

5 Celle-ci, intitulée "Réécriture et invention », revient sur la notion d'imitation des Anciens. Comme dans le chapitre consacré à Cicéron philosophe, l'auteur démontre que malgré la prédominance apparente de Sénèque comme source textuelle, Cicéron l'emporte comme modèle structurant de la pensée. À travers l'étude précise de cas particuliers, l'amour que Pétrarque porte à Cicéron se révèle être tout sauf un « culte " formaliste. Enfin, le dernier chapitre du livre aborde la question, que le titre du livre laissait attendre, du rapport entre la pratique épistolaire de Pétrarque et celle de Cicéron. Il s'appuie sur l'approche que la critique littéraire développe à l'égard de la Correspondance de Cicéron depuis quelques dizaines d'années, en rupture avec la perception, qui a longtemps prévalu, d'un corpus qui ne serait qu'une transcription fidèle de la réalité, voire une série d'anecdotes relativement superficielles, opposées à la profondeur morale des Lettres à Lucilius de Sénèque. L'auteur montre que la correspondance de Pétrarque, même si elle semble au premier abord plus proche de la correspondance de Sénèque par son caractère littéraire conscient, relève en réalité d'une conception qui puise à bien des égards ses origines dans la Correspondance à Atticus. La lettre est perçue comme relationnelle, mue par l'amitié, créant une illusion de présence et de conversation. Pétrarque développe toutes sortes de remarques sur l'écriture épistolaire que l'on peut rapprocher de la pratique cicéronienne, avec des similitudes de lexique qui ne doivent rien au hasard. La lettre pétrarquienne s'approprie également certains procédés de la lettre cicéronienne. Introspection, «dialogue de soi à soi ", et finalement lieu d'élaboration d'un moi en construction par l'écriture, la lettre pétrarquienne ouvre des voies à ses successeurs : l'épistolographie érasmienne ou l'essai montaignien.

$6 \mathrm{Au}$ total, cette démonstration claire, constamment argumentée et étayée de nombreuses citations, se lit avec un grand plaisir. Elle intéressera bien évidemment les spécialistes de la Renaissance et de l'humanisme; mais cette étude de la tradition vivante d'une des deux figures de proue de la littérature latine - Cicéron, Virgile s'adresse aussi aux amoureux des littératures antiques. En un temps où pour beaucoup, les œuvres de Cicéron sont au mieux connues par leur titre mais ne sont plus lues, cette étude donne à voir combien l'humanisme de Pétrarque allie érudition et approche affective, sensibilité littéraire et recherche existentielle, loin du formalisme pédant qu'on a souvent reproché, après la critique sévère émise par Érasme, aux cicéroniens $\mathrm{du} \mathrm{XVI}^{\mathrm{e}}$ siècle. 


\section{AUTEURS}

ANNE-HÉLÈNE KLINGER-DOLLÉ

Université de Toulouse-Jean Jaurès (UT2J)

dolle@univ-tlse2.fr 